\title{
Renal effects of metallothionein induction by zinc in vitro and in vivo
}

Moritz Schanz ${ }^{1}$, Lea Schaaf ${ }^{3}$, Juergen Dippon², Dagmar Biegger ${ }^{1,3}$, Peter Fritz ${ }^{3}$, Mark Dominik Alscher ${ }^{1}$ and Martin Kimmel ${ }^{1 *}$ (D)

\begin{abstract}
Background: Metallothionein (MTT) is an endogenous antioxidant that can be induced by both zinc (Zn) and ischemia. In kidneys, increased MTT expression exerts a putative protective role in diabetes and hypoxia. Our goal was to further investigate the behavior of MTT under the influence of $\mathrm{Zn}$ and hypoxia in vitro and in vivo.

Methods: MTT expression was measured in vitro in cell cultures of proximal tubular cells (LCC-PK1) by immunehistochemistry and real-time PCR after incubation with increasing concentrations of $\mathrm{Zn}$ under hypoxic and nonhypoxic conditions. In addition, in vivo studies were carried out in 54 patients to study MTT induction through Zn. This is a sub-study of a prospective, randomized, double-blind trial on prevention of contrast-media-induced nephropathy using Placebo, $\mathrm{Zn}$ and N-Acetylcysteine. Blood samples were obtained before and after 2 days p.o. treatment with or without $\mathrm{Zn}(60 \mathrm{mg})$. ELISA-based MTT level measurements were done to evaluate the effects of $\mathrm{Zn}$ administration. For in vivo analysis, we considered the ratio of $\mathrm{MTT}$ to baseline $\mathrm{MTT}(\mathrm{MTT} / \mathrm{MTT}$ ) and the ratio of eGFR (eGFR $/$ /eGFRo), correspondingly.
\end{abstract}

Results: In vitro quantitative immuno-histochemical analysis (IHC) and real-time PCR showed that at increasing levels of Zn (5, 10, and $15 \mu \mathrm{g} / \mathrm{ml}$ ) led to a progressive increase of MTTs: Median (IQR) expression of IHC also increased progressively from $0.10(0.09-0.12), 0.15(0.12-0.18), 0.25(0.25-0.27), 0.59(0.48-0.70)(p<0.0001)$. Median (IQR) expression of PCR: 0.59 (0.51-1.72), 1.62 (1.38-4.70), 3.58 (3.06-10.42) and $10.81(9.24-31.47)(p<0.0001) . \ln$ contrast, hypoxia did not change MTT-levels in vitro $(p>0.05)$.

In vivo no significant differences ( $p=0.96$ ) occurred in MTT-levels after 2 days of $Z n$ administration compared with no $\mathrm{Zn}$ intake. Nevertheless, there was a significant correlation between MTT (MTT $1 / M_{T} T_{0}$ ) and eGFR (eGFR $/ \mathrm{eGFR}_{0}$ ) in case of $\mathrm{Zn}$ administration ( $\mathrm{rho}=-0.49 ; 95 \%-\mathrm{Cl}$ : -0.78 to $-0.03 ; p=0.04$ ).

Conclusions: We found that Zn did induce MTTs in vitro, whereas hypoxia had no significant impact. In contrast, no significant increase of MTTs was detected after in vivo administration of Zn. However, there was a significant negative correlation between MTT and eGFR in vivo in case of Zn administration, this could indicate a protective role of MTTs in a setting of reduced kidney function, which is possibly influenced by Zn.

Trial registration: ClinicalTrials.gov Identifier: NCT00399256. Retrospectively registered 11/13/2006.

Keywords: Cell culture, Contrast medium, Hypoxia, Induction, Metallothionein, Zinc

\footnotetext{
* Correspondence: martin.kimmel@rbk.de

${ }^{1}$ Department of Internal Medicine, Division of General Internal Medicine and

Nephrology, Robert-Bosch Hospital Stuttgart, Auerbachstraße 110, 70376

Stuttgart, Germany

Full list of author information is available at the end of the article
} 


\section{Background}

Oxidative stress engendered by hypoxia and inflammation can lead to DNA damage and destruction of cell structures [1, 2]. Metallothioneins (MTTs) are potent endogenous antioxidants that can inactivate the free radicals that mediate oxidative stress [3]. MTTs are a group of 6-7 kDa polypeptides containing approx. 20 cysteine amino acids [4]. They regulate and control intracellular metal ion metabolism [5] and normally are able to bind zinc in mammals, which mediates the antioxidative protective effect [6]. Beyond that, MTTs potentially play a role in different types of cancer, including breast, prostate, or kidney tumors [7].

MTTs were originally discovered in horse kidneys as a cadmium carrier [8]. Besides many MTT-like proteins, there are 4 different MTTs isoforms discovered so far in humans, MT-1, MT-2, MT-3 and MT-4 with partially different concentrations depending on tissue type [9].

Several groups have reported protective effects of MTTs against oxidative damage and a reduction of oxidative stress [3, 10-12]. Tissue and cells have increased resistance to reactive oxygen species during MTT overexpression [13]. There are several known inducers of MTT polypeptides, including acute exercise in humans [14]. In rats, increased MTT expression occurs during ischemic acute kidney injury [15]. Zinc ( $\mathrm{Zn})$ is a strong inducer of MTTs in vitro in renal proximal tubular cells [16]. In vivo, Sullivan et al. [17] demonstrated that Zn supplementation in healthy participants increased MTT concentration in erythrocytes and monocytes.

MTTs seem to play a major protective role in renal tissues [18-20], and our goal was to further investigate the behavior of MTT under the influence of $\mathrm{Zn}$ and hypoxia in vitro in renal cells and in vivo in serum specimens.

\section{Methods}

\section{Cell culture}

Epithelial renal tubular cells from swine (Sus scrofa; LLCPK1) were obtained from A.H. Schinkel (Amsterdam, The Netherlands). The renal cells were cultured in Medium 199 (Invitrogen, Darmstadt, Germany) with added 100 U/ $\mathrm{ml}$ penicillin, $100 \mathrm{U} / \mathrm{ml}$ streptomycin, and $10 \%$ fetal bovine serum albumen (Invitrogen, Darmstadt, Germany).

Cultures were incubated at $37{ }^{\circ} \mathrm{C}$ in different environments:

I. : $4.5 \mathrm{~h}$ under normal conditions in cell culture cabinet $\left(5 \% \mathrm{CO}_{2}, 18 \% \mathrm{O}_{2}\right)$

II. : $24 \mathrm{~h}$ under normal conditions in cell culture cabinet $\left(5 \% \mathrm{CO}_{2}, 18 \% \mathrm{O}_{2}\right)$

III.: $4.5 \mathrm{~h}$ under hypoxia in cell culture cabinet (5\% $\mathrm{CO}_{2}, 3 \% \mathrm{O}_{2}$ )

IV.: $24 \mathrm{~h}$ under hypoxia in cell culture cabinet (5\% $\mathrm{CO}_{2}, 3 \% \mathrm{O}_{2}$ )
V. : $4.5 \mathrm{~h}$ under hypoxia $\left(5 \% \mathrm{CO}_{2}, 3 \% \mathrm{O}_{2}\right)$ and $19.5 \mathrm{~h}$ under normal conditions in cell culture cabinet $(5 \%$ $\left.\mathrm{CO}_{2}, 18 \% \mathrm{O}_{2}\right)$.

Cell cultures were placed in five 6-well plates (Greiner, Darmstadt, Germany), with $1 \times 10^{5}$ cells distributed per well. The swine cells were cultured for 3 days until they were densely populated (up to $70 \%$ in each well). The cells were treated with increasing concentrations of zinc sulfate (Merck, Darmstadt, Germany) levels. Specifically, 4 groups of tubular cell cultures were studied, using a control level of 0 , and then 5, 10, and $15 \mu \mathrm{g} / \mathrm{ml} \mathrm{ZnSO}_{4}$ to quantitate the effects of progressively increasing concentrations of the $\mathrm{Zn}$ ion.

\section{Real-time PCR}

RNA was isolated using the RNAeasy mini-kit (Qiagen, Hilden, Germany) according to the manufacturer's instructions. Only samples with an optical density (OD) of 260/280-ratio between 2.0 and 2.1 were used. RNA quality was analyzed using a Bioanalyzer (Agilent Technologies) and RNA integrity numbers (RIN) $>8$ were observed for all RNA samples. Concentrations were ascertained by $\mathrm{OD}\left(\mathrm{A}_{260}=1=40 \mu \mathrm{g} / \mathrm{ml}\right)$. For cDNA generation measurements, TaqMan Reverse Transcription Reagents (Applied Biosystems, Foster City, CA, USA) were used. Quantification of gene expression was performed through real-time PCR as previously described [16]. In brief, primers used for real-time PCR were MTT Reverse-Primer: 5'-ATG GAT CCC AAC TGC TCC T3'; and MTT Reverse-Primer: 5'-CAG CAG CTG CAC TTG TCC-3'. As a control, histone 3.3 was applied: Forward primer: 5' CCA CTG AAC TTC TGA TTC GC 3' and histone 3.3 reverse primer: $5^{\prime}$ GCG TGC TAG CTG GAT GTC TT 3' [16]. Real-time PCR using SYBR green was performed on a 7900 Real-Time PCR System (Applied Biosystems, Foster City, CA, USA) according to manufacturer's protocol. MTT mRNA levels were normalized to histone 3.3 expression.

\section{Immunohistochemistry}

For IHC analysis, cells were cultivated as described above. In this analysis the environments II, IV and III were used. After $24 \mathrm{~h}$, the cell cultures were prepared for IHC analysis: Cells were trypsinized and washed with culture medium. Cytospin preparation was performed with a Cytofuge 3 (Shandon, USA). Thereafter, samples were dried for $2 \mathrm{~h}$ at room temperature and stored at $-21^{\circ} \mathrm{C}$.

For analysis, specimens were thawed and fixed with $4 \%$ paraformaldehyde. For endogenous peroxidase blocking, $3 \% \mathrm{H}_{2} \mathrm{O}_{2}$ in methanol was used. Endogenous biotin was blocked by means of Avidin-Biotin-Blocking Kit (Linaris, USA), according to the manufacturer's 
recommendations. Specimen staining was performed by using the $\mathrm{ABC}$ method as described previously [21].

\section{Quantitative staining measurement of IHC MTT expression}

MTT immune-histochemical staining was quantified by light microscope (Carl Zeiss AG, Oberkochen, Germany) with an image analysis workstation, a microscope with computerized analysis [22]. For automated evaluation of MTT protein expression, the software-based image analysis system Tissue Studio v.3.6 (Definiens AG, Munich, Germany) was utilized.

The predefined analysis solution "Nuclei, Membranes and Cells" with the tasks of ROI detection, nucleus and membrane detection, and cell classification was used. Threshold settings for nucleus and cytoplasm detection were adjusted. Detected cells were sub-classified as negative, low, medium or high according to IHC staining intensity. The Tissue Studio Score was derived from the number of cells (IHC positive and negative) multiplied by the average IHC marker intensity.

\section{Study design and subjects}

The in vivo study is a secondary analysis of a prospective, randomized, double-blind trial on prevention of contrast media-induced nephropathy. In this study 18 patients received $60 \mathrm{mg} \mathrm{Zn}$ p.o. QD for 2 days before serum MTT measurements. Previously comparable doses were used [17, 23]. Furthermore we adhered to the lowest observed adverse effect level (LOAEL) of $60 \mathrm{mg} /$ day [24]. At higher oral doses increase of side effects could occur [25]. Patients receiving NAC or placebo $(n=36)$ served as control group. Inclusion criteria were age $\geq 18$ years and serum Creatinine $(\mathrm{sCr}) \geq$ $1.2 \mathrm{mg} / \mathrm{dl}$ or creatinine clearance $<50 \mathrm{ml} / \mathrm{min}$ (measured by a 12- or 24-h urine collection). Exclusion criteria were acute inflammatory disease, use of NSAID or metformin medication up to 3 days before the study, and abnormal findings in physical examination (e.g., signs of dehydration or inflammation). The detailed study protocol and population was as described by Kimmel et al. [26]. Written informed consent was obtained from all patients. The local ethics committee approved the study (Ethics committee of the University of Tuebingen: 296/ 2003) and it was registered at ClinicalTrials.gov (NCT00399256).

\section{Laboratory measurements}

In the patients, human MTT was measured by ELISA in serum specimens. A commercial kit (USCN Life Science Inc., Wuhan, and Houston, TX, USA) was used for this measurement and was applied according to the instruction manual (Cat. No.: E1119Hu). Zn was analyzed by atomic absorption spectrometry. Estimated glomerular filtration rate (eGFR) was calculated using the Chronic Kidney Disease Epidemiology Collaboration (CKD-EPI) equation [27].

\section{Statistical analysis}

Statistical analysis was performed by using Prism, GraphPad (La Jolla, CA, USA) and R Version 3.3 [28]. To compare means of groups, Welch's $t$-test and Welch's one-way ANOVA or Wilcoxon rank-sum test and Kruskal-Wallis test were used. To compare different statistical models with continuous outcomes, including interaction terms and multiple input variables, partial F-tests were performed. To examine variance homogeneity between groups, Bartlett's and Levene's tests were applied. To check for normality of distributions, the Shapiro-Wilk test and Q-Q plots were conducted. In cases of non-normally distributed data, log-transformation was considered. For in vivo analysis, we considered the ratio of MTT to baseline MTT $\left(\mathrm{MTT}_{1} / \mathrm{MTT}_{0}\right)$, and the ratio of eGFR $\left(\mathrm{eGFR}_{1} /\right.$ $\mathrm{eGFR}_{0}$ ), correspondingly. To obtain well-fitting linear statistical models, these ratios were logarithmized.

\section{Results \\ In vitro \\ Metallothionein induction in LLC-PK1 cell culture}

Immunohistochemical analysis with LLC-PK1 Quantitative analysis by means of Tissue Studio v.3.6 (Definiens AG, Munich, Germany) showed increasing MTTexpressions with rising $\mathrm{Zn}$ concentrations (Fig. 1, Fig. 2, and Table 1). Median (IQR) expression was 0.10 (0.07$0.12)$ in control, $0.15(0.12-0.18)$ in $\mathrm{Zn} 5 \mu \mathrm{g} / \mathrm{ml}(17.4 \mu \mathrm{M})$, $0.25(0.25-0.27)$ in $\mathrm{Zn} 10 \mu \mathrm{g} / \mathrm{ml}(34.8 \mu \mathrm{M})$ and $0.59(0.48-$ $0.70)$ in $\mathrm{Zn} 15 \mu \mathrm{g} / \mathrm{ml}(52.2 \mu \mathrm{M})$. This increase was statistically significant $(p<0.0001)$. The median quantitative MTT

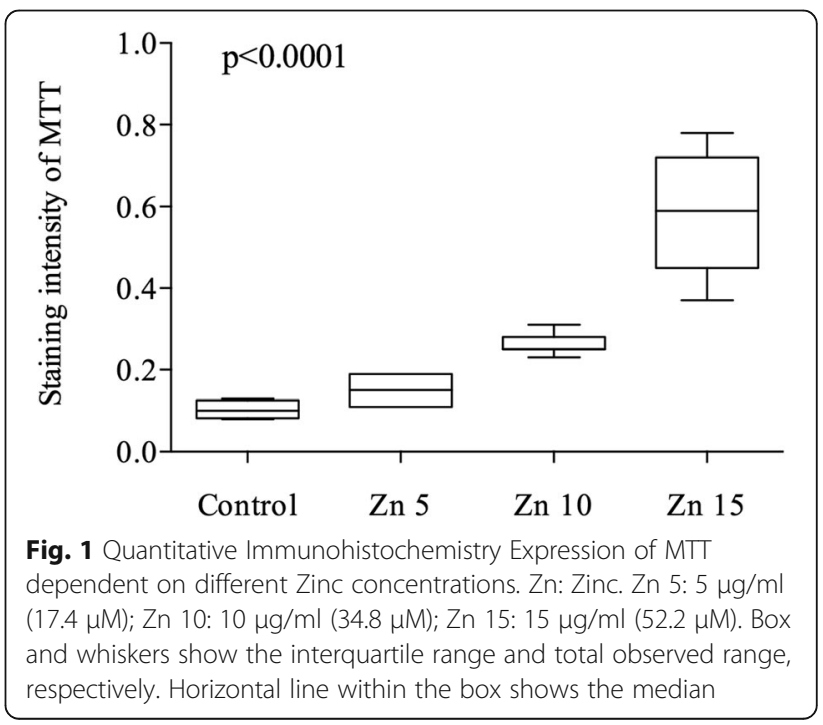




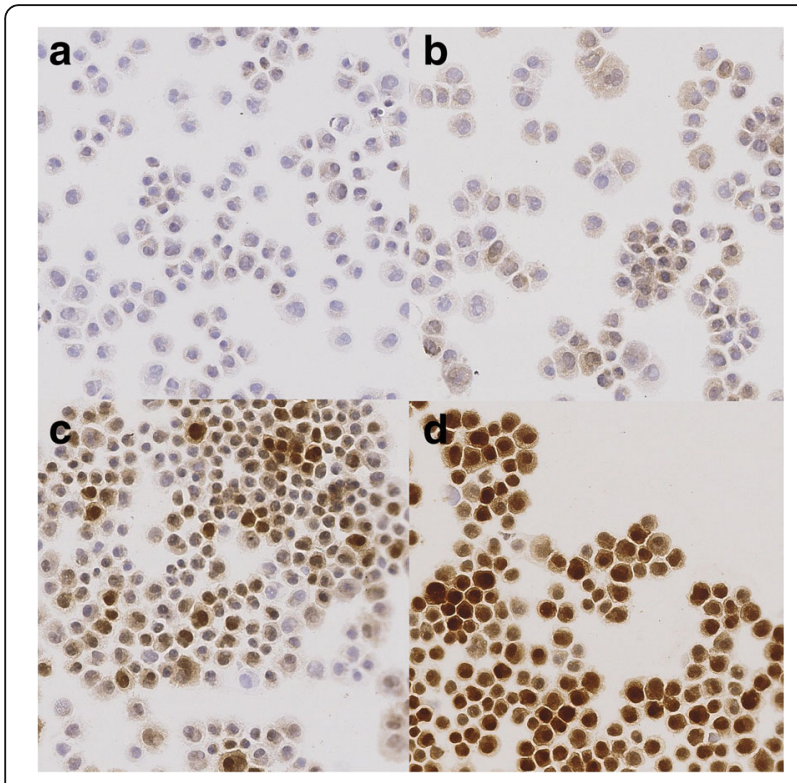

Fig. 2 a-d Quantitative Immunohistochemistry Expression of MTT dependent on different Zinc concentrations. A: control; B: Zinc $5 \mu \mathrm{g} /$ $\mathrm{ml}(17.4 \mu \mathrm{M})$; C: Zinc $10 \mu \mathrm{g} / \mathrm{ml}(34.8 \mu \mathrm{M})$; D: Zinc

$15 \mu \mathrm{g} / \mathrm{ml}(52.2 \mu \mathrm{M}))$

staining intensity of the cell culture cells under hypoxic conditions (IV and V) versus those under a non-hypoxic environment did not differ significantly $(p=0.83)$ (Fig. 3 and Table 2).

Real-time PCR analysis using LLC-PK1 cells In realtime PCR analysis, a significant increase of MTT expression was detectable $(p<0.0001)$ under rising $\mathrm{ZnSO}_{4}$ concentrations: control; $5 \mu \mathrm{g} / \mathrm{ml}(17.4 \mu \mathrm{M})$; $10 \mu \mathrm{g} / \mathrm{ml}(34.8 \mu \mathrm{M})$; and $15 \mu \mathrm{g} / \mathrm{ml}(52.2 \mu \mathrm{M})$. Median MTT (95\% CI) expression for normal environment (I) were 1.90 (1.49-2.43), 5.22 (4.09-6.66), 11.56 (9.06$14.76)$, and 34.94 (26.85-45.47). For the normal environment with longer incubation (II), median MTT expressions were 0.59 (0.46-0.75), 1.62 (1.27-2.05), 3.58 (2.82-4.55), and 10.81 (8.44-13.85). The three hypoxic environments showed a similar behavior: Under short hypoxic incubation (III), median MTT expression readings were $1.53(1.20-1.95), 4.18$ (3.28-5.34), 9.27 (7.26-11.83), and 28.00 (21.52-36.44), respectively. At

Table 1 Quantitative Immunohistochemistry Expression of MTT dependent on different Zinc concentrations

\begin{tabular}{lcclcll}
\hline Zinc concentration & $\mathrm{n}$ & Mean & $95 \% \mathrm{Cl}$ & Median & IQR & $p$-value \\
\hline Control & 4 & 0.10 & $0.07-0.14$ & 0.10 & $0.09-0.12$ & $<0.0001$ \\
$5 \mu \mathrm{g} / \mathrm{ml}(17.4 \mu \mathrm{M})$ & 6 & 0.15 & $0.11-0.19$ & 0.15 & $0.12-0.18$ & \\
$10 \mu \mathrm{g} / \mathrm{ml}(34.8 \mu \mathrm{M})$ & 7 & 0.26 & $0.24-0.28$ & 0.25 & $0.25-0.27$ & \\
$15 \mu \mathrm{g} / \mathrm{ml}(52.2 \mu \mathrm{M})$ & 7 & 0.59 & $0.45-0.72$ & 0.59 & $0.48-0.7$ & \\
\hline
\end{tabular}

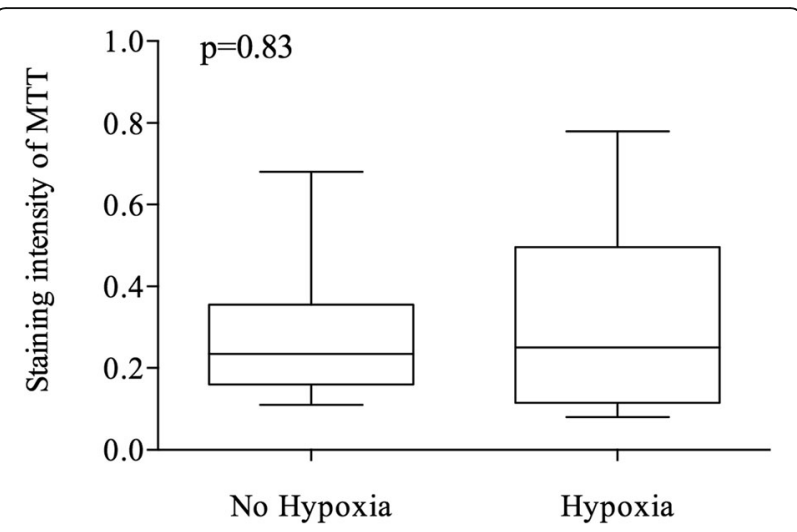

Fig. 3 Quantitative Immunohistochemistry Expression of MTT in the presence and absence of hypoxia. Box and whiskers show the interquartile range and total observed range, respectively. Horizontal line within the box shows the median

longer hypoxic incubation (IV) median MTT expression readings were $0.50(0.39-0.63), 1.37$ (1.08-1.74), 3.03 (2.38-3.85), and 9.15 (7.15-11.72). Hypoxic environment $\mathrm{V}$ also showed an increase of median MTT expressions with rising $\mathrm{Zn}$ concentrations: 0.51 (0.40$0.65), 1.39$ (1.09-1.78), 3.08 (2.42-3.93), and 9.32 (7.16-12.12). The increase was statistically significant $(p<0.0001)$ (Fig. 4 and Table 3$)$.

MTT expressions did not differ significantly between hypoxic and non-hypoxic environments. Between Environment I (normal) and III (hypoxic), only a trend to a decreased expression under hypoxic conditions was remarkable $(p=0.089)$. Between II (normal) and IV (hypoxic), a $p$-value of 0.23 was noted between environment II (normal) and IV (hypoxic) and a $p$-value of 0.25 between environment II and V (Table 3 and Fig. 5a, b and c).

\section{In vivo}

\section{Metallothionein induction in patients}

We compared MTT serum levels based on ELISA measurements in patients with moderately impaired kidney function that were receiving low osmolar contrast medium. We measured the increase of MTT $(\triangle \mathrm{MTT})$ in patients, comparing results between those who received 2 days of treatment with $\mathrm{Zn}, 60 \mathrm{mg}$ p.o. QD, to those with no Zn supplementation. No significant differences occurred between the two groups $(p>0.05)$ (Fig. 6).

We observed a significant negative correlation between MTT $\left(\mathrm{MTT}_{1} / \mathrm{MTT}_{0}\right)$ and eGFR $\left(\mathrm{eGFR}_{1} / \mathrm{eGFR}_{0}\right)$

Table 2 Quantitative Immunohistochemistry Expression of MTT dependent on different Zinc concentrations

\begin{tabular}{lllllll}
\hline Hypoxia & $\mathrm{n}$ & Mean & $95 \% \mathrm{Cl}$ & Median & IQR & $p$-value \\
\hline no & 8 & 0.285 & $0.13-0.44$ & 0.235 & $0.18-0.33$ & 0.83 \\
yes & 16 & 0.309 & $0.19-0.43$ & 0.25 & $0.13-0.47$ & \\
\hline
\end{tabular}




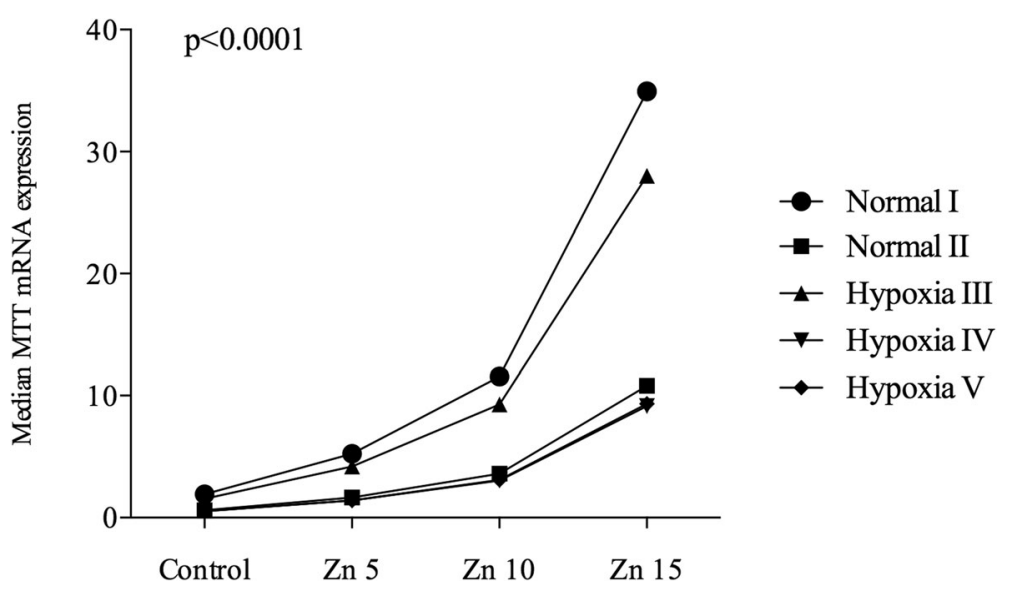

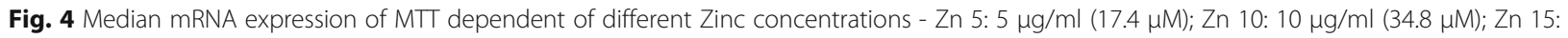
$15 \mu \mathrm{g} / \mathrm{ml}(52.2 \mu \mathrm{M})$. Zn: Zinc. Cell culture environments: I: $4.5 \mathrm{~h}$ normal conditions in cell culture cabinet $\left(5 \% \mathrm{CO}_{2}, 18 \% \mathrm{O}_{2}, 37^{\circ} \mathrm{C}\right) ; 11: 24 \mathrm{~h}$ normal conditions in cell culture cabinet $\left(5 \% \mathrm{CO}_{2}, 18 \% \mathrm{O}_{2}, 37^{\circ} \mathrm{C}\right)$; III: $4.5 \mathrm{~h}$ hypoxia cell culture cabinet $\left(5 \% \mathrm{CO}_{2}, 3 \% \mathrm{O}_{2}, 37^{\circ} \mathrm{C}\right)$; IV: $24 \mathrm{~h}$ hypoxia cell culture cabinet $\left(5 \% \mathrm{CO}_{2}, 3 \% \mathrm{O}_{2}, 37^{\circ} \mathrm{C}\right) ; \mathrm{V}: 4.5 \mathrm{~h}$ hypoxia cell culture cabinet $\left(5 \% \mathrm{CO}_{2}, 3 \% \mathrm{O}_{2}, 37^{\circ} \mathrm{C}\right)$ and $19.5 \mathrm{~h}$ normal conditions in cell culture cabinet $\left(5 \% \mathrm{CO}_{2}, 18 \% \mathrm{O}_{2}, 37^{\circ} \mathrm{C}\right)$

(rho $=-0.49 ; 95 \%$ CI: -0.78 to $-0.03 ; p=0.04$ ) in case of $\mathrm{Zn}$ administration, $\mathrm{Zn}$ had a significant impact on this correlation $(p=0.01)$ (Fig. 7). In absence of $\mathrm{Zn}$, no significant correlation between $\mathrm{MTT}\left(\mathrm{MTT}_{1} / \mathrm{MTT}_{0}\right)$ and eGFR $\left(\mathrm{eGFR}_{1} / \mathrm{eGFR}\right.$ ) could be detected (rho $=-0.01$, 95\%CI: -0.35 to 0.33 ; $p=0.96)$. Correspondingly, $\mathrm{Zn}$ influenced the correlation between $\mathrm{MTT}\left(\mathrm{MTT}_{1} / \mathrm{MTT}_{0}\right)$ and $\mathrm{sCr}\left(\mathrm{sCr}_{1} / \mathrm{sCr}_{0}\right)$ significantly $(p=0.01)$.

Serum $\mathrm{Zn}$ levels were measured at baseline and after $\mathrm{Zn}$ intake. Median (IQR) increase was $+11.5 \mu \mathrm{g} / \mathrm{dl}(-7$ to 21$)$ in the group with $\mathrm{Zn}$ treatment and $+3.0 \mu \mathrm{g} / \mathrm{dl}(-26$ to 22$)$ in those without $\mathrm{Zn}$ supplementation. However, this difference was not statistically significant $(p>0.05)$. According to baseline measurements $5 / 54$ (7.4\%) subjects had serum $\mathrm{Zn}$ levels below reference range $(<70 \mu \mathrm{g} / \mathrm{dL})$.

\section{Discussion}

MTT is an endogenous antioxidant and is known for its protective role against reactive oxygen species
$[3,6,11]$. Especially in the kidneys, MTT compounds play a major role, and seem to be involved in renal ageing [18]. Increased expression of MTT occurs in aged kidney tissues in the absence of chronic kidney disease. Predominant expression was described in proximal tubule cells [18]. In experimental settings, MTT induction in the kidney protects the tissues from oxidative stress [19]. In hypoxia, MTTs may play an important protective role: Wu et al. [29] demonstrated in a mouse model that depletion of MTTs worsened hypoxia-induced renal injury, and an increase in MTT-expression stabilizes hypoxia-inducible factor in the kidney [10]. Moreover, kidneys were less susceptible for hypoxia-induced apoptosis in a setting of overexpression of MT2A [18]. Given the known protective effects and the possibility of MTTinduction through $\mathrm{Zn}$, the influence of $\mathrm{Zn}$ on diabetic damages was evaluated. In these studies, $\mathrm{Zn}$ treatment protected kidneys from diabetic damage [11, 20].

Table 3 Median mRNA expression of MTT dependent on different Zinc concentrations under different hypoxic (III, IV) and nonhypoxic (I, II) environments. Cell culture environments: I: $4.5 \mathrm{~h}$ normal conditions in cell culture cabinet $\left(5 \% \mathrm{CO}_{2}, 18 \% \mathrm{O}_{2}, 37^{\circ} \mathrm{C}\right)$; II: $24 \mathrm{~h}$ normal conditions in cell culture cabinet $\left(5 \% \mathrm{CO}_{2}, 18 \% \mathrm{O}_{2}, 37^{\circ} \mathrm{C}\right)$; III: 4.5 h hypoxia cell culture cabinet $\left(5 \% \mathrm{CO}_{2}, 3 \% \mathrm{O}_{2}, 37{ }^{\circ} \mathrm{C}\right)$; IV: $24 \mathrm{~h}$ hypoxia cell culture cabinet $\left(5 \% \mathrm{CO}_{2}, 3 \% \mathrm{O}_{2}, 37^{\circ} \mathrm{C}\right) ; \mathrm{V}: 4.5 \mathrm{~h}$ hypoxia cell culture cabinet $\left(5 \% \mathrm{CO}_{2}, 3 \% \mathrm{O}_{2}, 37^{\circ} \mathrm{C}\right)$ and $19.5 \mathrm{~h}$ normal conditions in cell culture cabinet $\left(5 \% \mathrm{CO}_{2}, 18 \% \mathrm{O}_{2}, 37^{\circ} \mathrm{C}\right)$

\begin{tabular}{|c|c|c|c|c|c|c|}
\hline & \multicolumn{6}{|c|}{ Median MTT expression (95\% Cl) } \\
\hline & Zinc concentration & Control & $5 \mu \mathrm{g} / \mathrm{ml}(17.4 \mu \mathrm{M})$ & $10 \mu \mathrm{g} / \mathrm{ml}(34.8 \mu \mathrm{M})$ & $15 \mu \mathrm{g} / \mathrm{ml}(52.2 \mu \mathrm{M})$ & $p$-value \\
\hline \multirow[t]{6}{*}{ Environment } & Normal I & $1.90(1.49-2.43)$ & $5.22(4.09-6.66)$ & $11.56(9.06-14.76)$ & $34.94(26.85-45.47)$ & 0.089 \\
\hline & Hypoxia III & $1.53(1.20-1.95)$ & $4.18(3.28-5.34)$ & $9.27(7.26-11.83)$ & $28.00(21.52-36.44)$ & \\
\hline & Normal ॥ & $0.59(0.46-0.75)$ & $1.62(1.27-2.05)$ & $3.58(2.82-4.55)$ & $10.81(8.44-13.85)$ & 0.23 \\
\hline & Hypoxia IV & $0.50(0.39-0.63)$ & $1.37(1.08-1.74)$ & $3.03(2.38-3.85)$ & $9.15(7.15-11.72)$ & \\
\hline & Normal II & $0.59(0.46-0.75)$ & $1.62(1.27-2.05)$ & $3.58(2.82-4.55)$ & $10.81(8.44-13.85)$ & 0.25 \\
\hline & Hypoxia V & $0.51(0.40-0.65)$ & $1.39(1.09-1.78)$ & 3.08 (2.42-3.93) & $9.32(7.16-12.12)$ & \\
\hline
\end{tabular}



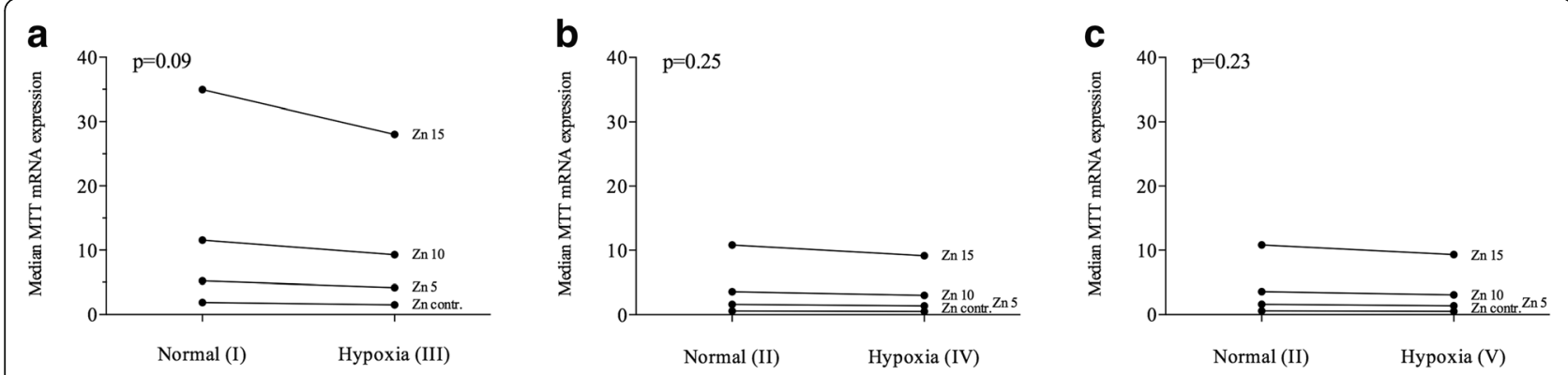

Fig. 5 a-c Median mRNA expression of MTT: The effect of different hypoxic environments (III, IV) compared to non-hypoxic conditions (I, II) with different Zn-concentrations. Zn: Zinc. Zn 5: $5 \mu \mathrm{g} / \mathrm{ml}(17.4 \mu \mathrm{M}) ; \mathrm{Zn}$ 10: $10 \mu \mathrm{g} / \mathrm{ml}(34.8 \mu \mathrm{M}) ; \mathrm{Zn}$ 15: $15 \mu \mathrm{g} / \mathrm{ml}(52.2 \mu \mathrm{M})$. Cell culture environments: I: $4.5 \mathrm{~h}$ normal conditions in cell culture cabinet $\left(5 \% \mathrm{CO}_{2}, 18 \% \mathrm{O}_{2}, 37^{\circ} \mathrm{C}\right) ; \mathrm{ll}: 24 \mathrm{~h}$ normal conditions in cell culture cabinet $\left(5 \% \mathrm{CO}_{2}, 18 \% \mathrm{O}_{2}, 37^{\circ} \mathrm{C}\right)$; III: 4.5 h hypoxia cell culture cabinet $\left(5 \% \mathrm{CO}_{2}, 3 \% \mathrm{O}_{2}, 37^{\circ} \mathrm{C}\right)$; IV: 24 h hypoxia cell culture cabinet $\left(5 \% \mathrm{CO}_{2}, 3 \% \mathrm{O}_{2}, 37^{\circ} \mathrm{C}\right)$; V: $4.5 \mathrm{~h}$ hypoxia cell culture cabinet $\left(5 \% \mathrm{CO}_{2}, 3 \% \mathrm{O}_{2}, 37^{\circ} \mathrm{C}\right)$ and $19.5 \mathrm{~h}$ normal conditions in cell culture cabinet $\left(5 \% \mathrm{CO}_{2}, 18 \% \mathrm{O}_{2}, 37^{\circ} \mathrm{C}\right)$

In our in-vitro studies, we found that $\mathrm{Zn}$ can induce MTT in renal tubular cells, as was reported previously [16]. We found significant increases of MTT levels in quantitative IHC and real-time PCR with augmented $\mathrm{Zn}$ concentrations $(p<0.0001)$. In contrast, under hypoxic conditions, no increase of MTT-expression was detected in renal cell cultures by IHC and PCR $(p>0.05)$. This is surprising, because previous studies in vivo reported that MTT increased under hypoxic conditions [15].

The interaction between hypoxia and MTT expression may be complex. It is known that many genes are upregulated during hypoxia [10], and overexpression may be mediated by inflammation which results from in vivo hypoxia [30]. Inflammation is known to increase MTT levels [31], but inflammation requires the interaction of, among others, inflammatory cells, vessels, and cytokines [32]. In vitro this environment does not exist and therefore no increased MTT expression was detectable.

Despite its main intracellular location, MTT also occurred in lower quantity in serum specimens [33, 34]. Similar behaviour of serum MTT in reaction to stress or administered metals suggests that it seems to be adequate

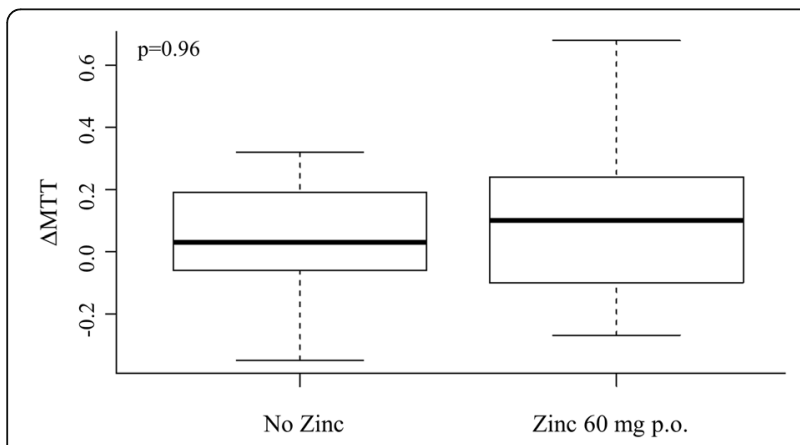

Fig. 6 Median $\triangle M T T$ in correlation of zinc administration in humans. MTT units: $\mathrm{ng} / \mathrm{mL} ; \mathrm{Zn}=0: n=36 ; \mathrm{Zn}=1: n=18$. Box and whiskers show the interquartile range and total observed range, respectively. Horizontal line within the box shows the median to use serum MTT as a marker of intracellular MTT response [35, 36]. Interestingly, when we analyzed blood samples in our prospective study of prevention of contrast media-induced nephropathy, we found that $\mathrm{Zn}$ had no measurable effect on MTTs levels in serum samples $(p>$ $0.05)$. This result contradicts previous findings $[16,17]$. In summary, according to our present data, induction of MTTs through short-term Zn supplementation does not appear to be significant in patients with impaired kidney function, after exposure to contrast media.

The population and the method of MTT-measurement in the previous in vivo studies differed significantly from those in our trial [17]. Whereas Sullivan et al. [17] evaluated healthy participants, our patients presented with preexisting renal dysfunction. In their study they supplemented over a longer time period and measured MTT in erythrocytes and monocytes. Therefore a comparison seems to be debatable. Additionally, it is possible that the iodinated contrast media could have affected the zinc-MTT-interaction.

Our data indicate that $\mathrm{Zn}$ supplementation did not induce MTTs in vivo compared with no $\mathrm{Zn}$ intake, although we found there was a significant association of MTT with eGFR (rho $=-0.49 ; p=0.04$ ) in case of $\mathrm{Zn}$ administration. $\mathrm{Zn}$ influenced this correlation significantly $(p=0.01)$. That could imply a negative correlation between eGFR and MTT in reduced kidney function, which could be an indication of a protective role for MTTs. Interestingly, previous studies have shown no MTT increase under chronic hypoxic conditions and during development of chronic kidney disease. Wu et al. [29] demonstrated that during intermittent hypoxia for $>8$ weeks accompanied by renal fibrosis, no increase in MTTs was detectable, whereas initially an increased expression of MTTs occurred. Sun et al. [37] also showed that short-term oxidative stress (during hypoxia) induced MTTs, whereas long-term hypoxia did not affect MTTs. The results suggest that in chronic impaired kidney function itself, MTT induction is not evident, whereas in further decline of kidney function, induction of MTTs can 


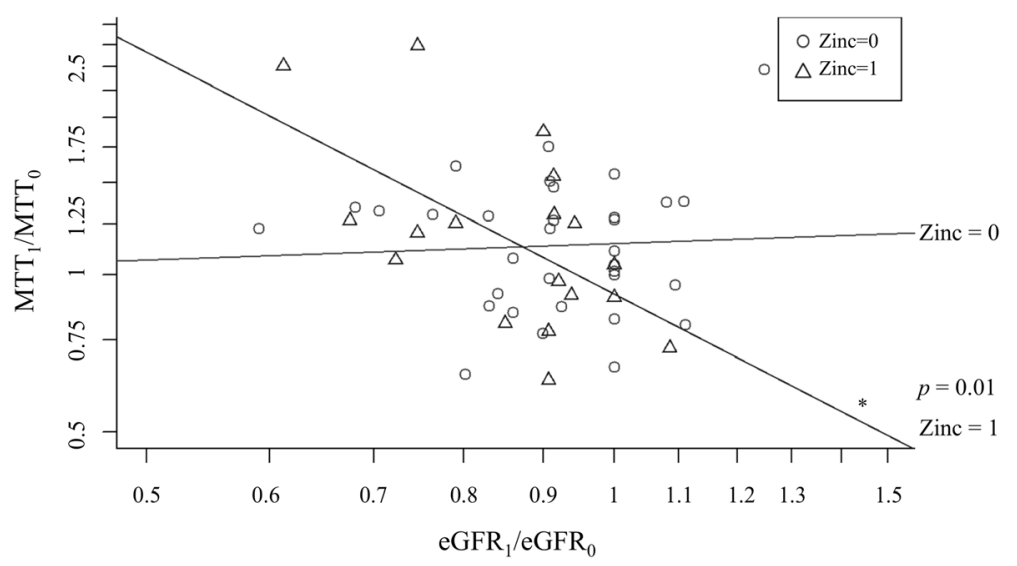

Fig. 7 Interaction of $M T T\left(M T_{1} / M T_{0}\right)$ and eGFR (eGFR $/$ /eGFR $)$ in the presence $(\Delta)$ and absence (o) of zinc. Correlation of $M T T\left(M T_{1} / M T T_{0}\right)$ and eGFR (eGFR $/ \mathrm{eGFR}_{0}$ ) in case of $\mathrm{Zn}$ administration: $\mathrm{Rho}=-0.49 ; 95 \% \mathrm{Cl}:-0.78$ to $-0.03 ; p=0.04$. Addition of Zinc has a significant impact ( $p=0.01$ ). No significant correlation without Zn administration: Rho $=-0.01,95 \% \mathrm{Cl}:-0.35$ to $0.33 ; p=0.96$. MTT: Metallothionein. eGFR: estimated glomerular filtration rate. Units: MMT: $\mathrm{ng} / \mathrm{mL}$; eGFR: $\mathrm{mL} / \mathrm{min}$. $Z n=0: n=36 ; Z n=1: n=18$

be detected in case of $\mathrm{Zn}$ administration. We cannot rule out the possibility that a reduced renal excretion could also have influenced serum MTT levels, but there are two observations which do not support these concerns: Zn significantly influences the correlation between eGFR and MTT and in absence of $\mathrm{Zn}$ no such association was evident.

We have to emphasize that the increase of $\mathrm{Zn}$ in serum did not differ significantly $(p>0.05)$ between subjects receiving $\mathrm{Zn}$ and those who did not. The lacking increase could be originate from the particular issue with $\mathrm{Zn}$ serum measurements itself: First, plasma $\mathrm{Zn}$ levels are known to change very slowly as response to changes in $\mathrm{Zn}$ intake [38] and, after ingestion, $\mathrm{Zn}$ is primarily taken up by the liver before a redistribution to the whole body occurs [39]. Second, the plasma $\mathrm{Zn}$ amount is less than $1 \%$ of the whole $\mathrm{Zn}$ storage because it is mainly kept intracellular in the muscles and bones [40] and known to be a poor indicator for total $\mathrm{Zn}$ amount. This is due to the fact that the plasma levels are highly affected by multiple factors such as circadian fluctuations and cytokinerelated influences [41-43]. Thus, measurements of plasma $\mathrm{Zn}$ concentration to assess $\mathrm{Zn}$ status are in general known to be diagnostically inconclusive [25].

Nevertheless we cannot exclude that longer or higher doses of $\mathrm{Zn}$ supplementation could have led to an increase in plasma $\mathrm{Zn}$ which also could have influenced MTT levels. But our study design did not allow for longer intake and the increase of side effects at higher doses did not allow for raising the dosage.

\section{Conclusions}

In conclusion, we found that Zn can induce MTTs in vitro, but in vivo $\mathrm{Zn}$ supplementation of $60 \mathrm{mg}$ per day had no significant effect on MTT-induction. However, there was a significant positive correlation between MTT and eGFR in vivo in case of Zn administration, which could indicate a protective role of MTTs in a setting of reduced kidney function, which is possibly influenced by $\mathrm{Zn}$.

\section{Abbreviations}

CKD-EPI: Chronic Kidney Disease Epidemiology Collaboration; IHC: Immunohistochemistry; LOAEL: Lowest observed adverse effect level; MTT: Metallothionein; p.o.: Per os, per mouth; PCR: Polymerase chain reaction; sCr: Serum Creatinine; Zn: Zinc

\section{Acknowledgements}

We gratefully acknowledge Andrea Jarmuth for excellent technical assistance and Elke Schaeffeler for support of gene expression analyses.

\section{Funding}

This study was supported by the Robert-Bosch Foundation (Stuttgart, Germany) by providing a research grant. The funder had no influence on study design, conduction or analysis of the study.

\section{Availability of data and materials}

All data underlying the findings are within the paper or available upon reasonable request from the corresponding author.

\section{Authors' contributions}

All authors made substantial contributions to the scientific process of this study resulting in preparation of this paper. MK, PF, and MDA designed the study. JD, MK, MS, and PF had full access to all data, contributed to the analysis and take responsibility for the integrity of the data and the accuracy of the data analysis. Data collection: MK, MS, DB, PF, and LS gathered data. All authors reviewed the data and participated in discussions related to interpretation. MS wrote the first draft of the manuscript. All authors contributed to drafting or editing the manuscript and approved the final draft.

\section{Competing interests}

The authors declare that they have no competing interests.

\section{Consent to publication}

Not applicable.

Ethics approval and consent to participate

Ethics approval and consent was given by the local ethics committee (Ethics committee of the University of Tuebingen: 296/2003). The study was 
registered retrospectively (11/13/2006) at ClinicalTrials.gov (NCT00399256) Written informed consent was obtained from all patients.

\section{Publisher's Note}

Springer Nature remains neutral with regard to jurisdictional claims in published maps and institutional affiliations.

\section{Author details}

'Department of Internal Medicine, Division of General Internal Medicine and Nephrology, Robert-Bosch Hospital Stuttgart, Auerbachstraße 110, 70376 Stuttgart, Germany. ${ }^{2}$ Department of Mathematics, University of Stuttgart, Stuttgart, Germany. ${ }^{3}$ Dr. Margarete Fischer-Bosch Institute of Clinical Pharmacology, Stuttgart, Germany.

Received: 13 January 2017 Accepted: 7 March 2017

Published online: 16 March 2017

\section{References}

1. Poli G, Leonarduzzi G, Biasi F, Chiarpotto E. Oxidative stress and cell signalling. Curr Med Chem. 2004;11(9):1163-82.

2. Cadenas E. Biochemistry of oxygen toxicity. Annu Rev Biochem. 1989;58:79-110.

3. Shimazu T, Hirschey MD, Newman J, He W, Shirakawa K, Le Moan N, Grueter CA, Lim H, Saunders LR, Stevens RD, Newgard CB, Farese RV, de Cabo R, Ulrich S, Akassoglou K, Verdin E. Suppression of oxidative stress by $\beta$-hydroxybutyrate, an endogenous histone deacetylase inhibitor. Science. 2013;339(6116):211-4.

4. Romero-Isart N, Vasák M. Advances in the structure and chemistry of metallothioneins. J Inorg Biochem. 2002;88(3-4):388-96.

5. Kägi JH, Schäffer A. Biochemistry of metallothionein. Biochemistry. 1988; 27(23):8509-15.

6. Kägi JH. Overview of metallothionein. Methods Enzymol. 1991;205:613-26.

7. Cherian MG, Jayasurya A, Bay BH. Metallothioneins in human tumors and potential roles in carcinogenesis. Mutat Res. 2003;533(1-2):201-9.

8. Margoshes M, Vallee BL. A cadmium protein from equine kidney cortex. J Am Chem Soc. 1957;79(17):4813-4.

9. Vašák M, Meloni G. Chemistry and biology of mammalian metallothioneins. J Biol Inorg Chem. 2011;16(7):1067-78.

10. Kojima I, Tanaka T, Inagi R, Nishi H, Aburatani H, Kato H, Miyata T, Fujita T, Nangaku M. Metallothionein is upregulated by hypoxia and stabilizes hypoxia-inducible factor in the kidney. Kidney Int. 2009;75(3):268-77.

11. Sun W, Wang Y, Miao X, Zhang L, Xin Y, Zheng S, Epstein PN, Fu Y, Cai L. Renal improvement by zinc in diabetic mice is associated with glucose metabolism signaling mediated by metallothionein and Akt, but not Akt2. Free Radic Biol Med. 2014:68:22-34.

12. Maret $\mathbf{W}$. Fluorescent probes for the structure and function of metallothionein. J Chromatogr B Analyt Technol Biomed Life Sci. 2009; 877(28):3378-83.

13. Viarengo A, Burlando B, Ceratto N, Panfoli I. Antioxidant role of metallothioneins: a comparative overview. Cell Mol Biol (Noisy-le-grand). 2000;46(2):407-17.

14. Podhorska-Okołów M, Dziegiel P, Dolińska-Krajewska B, Dumańska M, Cegielski M, Jethon Z, Rossini K, Carraro U, Zabel M. Expression of metallothionein in renal tubules of rats exposed to acute and endurance exercise. Folia Histochem Cytobiol. 2006;44(3):195-200.

15. Takahashi T, Itano Y, Noji S, Matsumoto K, Taga N, Mizukawa S, Toda N, Matsumi M, Morita K, Hirakawa M. Induction of renal metallothionein in rats with ischemic renal failure. Res Commun Mol Pathol Pharmacol. 2001; 110(3-4):147-60

16. Alscher DM, Braun N, Biegger D, Stuelten C, Gawronski K, Mürdter TE, Kuhlmann U, Fritz P. Induction of metallothionein in proximal tubular cells by zinc and its potential as an endogenous antioxidant. Kidney Blood Press Res. 2005;28(3):127-33.

17. Sullivan VK, Burnett FR, Cousins RJ. Metallothionein expression is increased in monocytes and erythrocytes of young men during zinc supplementation. J Nutr. 1998;128(4):707-13.

18. Leierer J, Rudnicki M, Braniff SJ, Perco P, Koppelstaetter C, Mühlberger I, Eder S, Kerschbaum J, Schwarzer C, Schroll A, Weiss G, Schneeberger S, Wagner S, Königsrainer A, Böhmig GA, Mayer G. Metallothioneins and renal ageing. Nephrol Dial Transplant. 2016;31(9):1444-52.
19. Sharma R, Sharma M, Datta PK, Savin VJ. Induction of metallothionein-I protects glomeruli from superoxide-mediated increase in albumin permeability. Exp Biol Med (Maywood). 2002;227(1):26-31.

20. Özcelik D, Nazıroglu M, Tunçdemir M, Çelik Ö, Öztürk M, Flores-Arce MF. Zinc supplementation attenuates metallothionein and oxidative stress changes in kidney of streptozotocin-induced diabetic rats. Biol Trace Elem Res. 2012;150(1-3):342-9.

21. Li X, Chen H, Epstein PN. Metallothionein protects islets from hypoxia and extends islet graft survival by scavenging most kinds of reactive oxygen species. J Biol Chem. 2004;279(1):765-71.

22. Fritz $P$, Multhaupt $H$, Hoenes J, Lutz D, Doerrer $R$, Schwarzmann P, Tuczek HV. Quantitative immunohistochemistry. Theoretical background and its application in biology and surgical pathology. Prog Histochem Cytochem. 1992;24(3):1-53.

23. Macknin ML, Piedmonte M, Calendine C, Janosky J, Wald E. Zinc gluconate lozenges for treating the common cold in children: a randomized controlled trial. JAMA. 1998;279(24):1962-7.

24. International Zinc Nutrition Consultative G, Brown KH, Rivera JA, Bhutta Z, Gibson RS, King JC, Lonnerdal B, Ruel MT, Sandtrom B, Wasantwisut E, Hotz C. International Zinc Nutrition Consultative Group (IZiNCG) technical document \#1. Assessment of the risk of zinc deficiency in populations and options for its control. Food Nutr Bull. 2004;25(1 Suppl 2):S99-203.

25. Holt RRU-A JY, Keen CL. Zinc. In: Erdman JW, Macdonald IA, Zeisel SH, editors. Present Knowledge in Nutrition. Ames: Wiley-Blackwell; 2012. p. 521-39.

26. Kimmel M, Butscheid M, Brenner S, Kuhlmann U, Klotz U, Alscher DM. Improved estimation of glomerular filtration rate by serum cystatin $C$ in preventing contrast induced nephropathy by $\mathrm{N}$-acetylcysteine or zincpreliminary results. Nephrol Dial Transplant. 2008;23(4):1241-5.

27. Levey AS, Stevens LA, Schmid CH, Zhang YL, Castro 3rd AF, Feldman HI, Kusek JW, Eggers P, Van Lente F, Greene T, Coresh J, Ckd EPI. A new equation to estimate glomerular filtration rate. Ann Intern Med. 2009;150(9):604-12.

28. R Development Core Team. R: A language and environment for statistical computing. Vienna: R Foundation for Statistical Computing; 2016.

29. Wu H, Zhou S, Kong L, Chen J, Feng W, Cai J, Miao L, Tan Y. Metallothionein deletion exacerbates intermittent hypoxia-induced renal injury in mice. Toxicol Lett. 2015;232(2):340-8.

30. Eltzschig HK, Carmeliet P. Hypoxia and inflammation. N Engl J Med. 2011; 364(7):656-65.

31. Inoue K, Takano H, Shimada A, Satoh M. Metallothionein as an antiinflammatory mediator. Mediators Inflamm. 2009;2009:101659.

32. Menkin V. Biochemical Mechanisms in Inflammation. Br Med J. 1960; 1(5185):1521-8

33. Mehra RK, Bremner I. Development of a radioimmunoassay for rat liver metallothionein-I and its application to the analysis of rat plasma and kidneys. Biochem J. 1983;213(2):459-65.

34. Garvey JS, Chang CC. Detection of circulating metallothionein in rats injected with zinc or cadmium. Science. 1981;214(4522):805-7.

35. Sato M, Mehra RK, Bremner I. Measurement of plasma metallothionein-I in the assessment of the zinc status of zinc-deficient and stressed rats. J Nutr. 1984;114(9):1683-9.

36. Hidalgo J, Giralt M, Garvey JS, Armario A. Physiological role of glucocorticoids on rat serum and liver metallothionein in basal and stress conditions. Am J Physiol. 1988;254(1 Pt 1):E71-8.

37. Sun W, Yin X, Wang Y, Tan Y, Cai L, Wang B, Cai J, Fu Y. Intermittent hypoxia-induced renal antioxidants and oxidative damage in male mice: hormetic dose response. Dose Response. 2012;11(3):385-400.

38. King JC, Shames DM, Lowe NM, Woodhouse LR, Sutherland B, Abrams SA, Turnlund JR, Jackson MJ. Effect of acute zinc depletion on zinc homeostasis and plasma zinc kinetics in men. Am J Clin Nutr. 2001;74(1):116-24.

39. Hambidge KMC CE, Krebs NF. Zinc. In: Mertz W, editor. Trace Elements in Human and Animal Nutrition, vol. 2. Orlando: Academic; 1986. p. 1-137.

40. Iyengar GV. Reevaluation of the trace element content in Reference Man. Radiat Phys Chem. 1998;51(4-6):545-60.

41. King JC. Zinc: an essential but elusive nutrient. Am J Clin Nutr. 2011;94(2):679S-84.

42. Hurley LS, Gordon P, Keen CL, Merkhofer L. Circadian variation in rat plasma zinc and rapid effect of dietary zinc deficiency. Proc Soc Exp Biol Med. 1982;170(1):48-52.

43. Kiilerich S, Christensen MS, Naestoft J, Christiansen C. Determination of zinc in serum and urine by atomic absorption spectrophotometry; relationship between serum levels of zinc and proteins in 104 normal subjects. Clin Chim Acta. 1980;105(2):231-9. 